\section{SOI: $1.1 /$ TAS DOI: $10.15863 /$ TAS International Scientific Journal Theoretical \& Applied Science}

p-ISSN: 2308-4944 (print) e-ISSN: 2409-0085 (online)

Year: 2018 Issue: 09 Volume: 65

Published: $24.09 .2018 \quad$ http://T-Science.org
Hafiz Muhammad Ayyaz Afzal Post graduate Resident in Nishter Hospital Multan,

Pakistan.

doctorayyaz9@gmail.com

Verda Zulfiqar

Doctor in Jinnah Hospital Lahore, Pakistan shahryar095@gmail.com

Sidra Kayani

Doctor in Holy Family Hospital Rawalpindi,

Pakistan.

sidkayani1@gmail.com

\title{
INCIDENCE AND PRESENTATION OF TUBERCULOUS MENINGITIS
}

\begin{abstract}
Objective: This study was conducted to determine incidence and presentation of tuberculous meningitis in male vs female populations.

Design and Duration: This is a cross sectional study of descriptive type. This comprises on 7 months duration from January 2018 to July 2018.

Setting: This study was conducted in Nishter Hospital Multan Pakistan.

Patients and Methods: All patients presented in emergency department or outpatient door of study institution with signs and symptoms of meningitis were evaluated and out of them patients with tuberculous meningitis were selected for study. These cases were belonging to both male and female populations and having different age groups. Proper history was taken, thorough physical examination was done, CT scan was done in all cases and where CT scan was not conclusive, MRI was done. Lumber Puncture was done and $5 \mathrm{ml} C S F$ taken from all cases and sent for examination to the hospital laboratory. All necessary investigations were done such as CBC with ESR, RFTs, LFTs. A performa was designed containing relevant questions such as age, presenting complaints, durations of disease, family history of tuberculosis or in the patient himself and any associated disease etc. Those cases having any other chronic disease with TBM were not included in the study. Data collected was analyzed using statistical software and Microsoft office version 2017. Results were calculated as frequencies and percentages. Tables and graphs were used to express the results.

Results: There were total 116 cases diagnosed with tuberculous meningitis presenting during study duration. $55.2 \%$ were female and $44.8 \%$ were male patients. Range of their ages was $15-73$ years with mean age of $45 \pm 17.8$ years. There were $17.2 \%$ female and $26.9 \%$ male cases between $15-25$ years, $20.3 \%$ female and $30.8 \%$ male cases between 26-35 years, $23.4 \%$ female and $17.3 \%$ male between $36-45$ years, $15.6 \%$ female and $11.5 \%$ male between 46-55 years and $10.9 \%$ female and $5.8 \%$ male cases were above 65 years. Presenting complaints were fever in $92.2 \%$ females and $88.5 \%$ male cases, headache was present in $96.8 \%$ female and $92.3 \%$ male cases, signs of meningism were present in $79.7 \%$ female and $71.2 \%$ male cases and $18.7 \%$ female and $9.6 \%$ male cases presented in coma. Findings on CT scan were hydrocephalus in $67.2 \%$ cases, edema in $36.2 \%$ and infarction in $11.2 \%$ cases. On MRI brain hydrocephalus was seen in 81(69.8\%) cases, tuberculomas in 86(74\%) and infarcts in 14(12.1\%) were seen. Solitary tuberculomas were present in $22 \%$ cases and multiple in $64 \%$ cases.

Conclusion: Tuberculous meningitis is a common form of meningitis occurring in both genders but frequently occurs in females. CT scan and MRI are very helpful in diagnosing TBM. Most common presenting symptoms were fever, headache and meningism while coma may be present in few cases.
\end{abstract}

Key words: Tuberculous meningitis, Meningism, presentation of meningitis.

Language: English

Citation: Ayyaz Afzal HM, Zulfiqar V, Kayani S (2018) INCIDENCE AND PRESENTATION OF TUBERCULOUS MENINGITIS. ISJ Theoretical \& Applied Science, 09 (65): 134-138.

Soi: http://s-o-i.org/1.1/TAS-09-65-21 Doi: crossef https://dx.doi.org/10.15863/TAS.2018.09.65.21

\section{INTRODUCTION}

Meningitis is a very common neurological disease in which inflammation of leptpmeningis occur. ${ }^{1}$ This leads to hydrocephalus of non obstructing type. Intracranial pressure is raised causing headache and cranial nerves palsy, decreased in vision etc. Meningitis may be due to viral or bacterial infection and trauma., ${ }^{2,3}$ Mycobacterium tuberculosis is a common cause of meningitis. It is common in people having previously tuberculous infection or positive family history of pulmonary tuberculosis. There are various investigations for diagnosing TBM such as CT scan brain, MRI brain and CSF culture and examination. In most of the 
cases mycobacterium is isolated on CSF culture. Suitable antibiotic treatment is very effective against it. Initial management includes airway management , maintaining circulation assessing GCS and management of fever and broad spectrum antibiotic therapy until unless culture sensitivity is obtained. ${ }^{4-6}$ All patients presented in emergency department or outpatient door of study institution with signs and symptoms of meningitis were evaluated and out of them patients with tuberculous meningitis were selected for study. These cases were belonging to both male and female populations and having different age groups. Proper history was taken, thorough physical examination was done, CT scan was done in all cases and where CT scan was not conclusive, MRI was done. Lumber Puncture was done and $5 \mathrm{ml} \mathrm{CSF} \mathrm{taken} \mathrm{from} \mathrm{all} \mathrm{cases} \mathrm{and} \mathrm{sent} \mathrm{for}$ examination to the hospital laboratory. In CT scan features of TBM reveal clearly such as hydrocephalus, presence of tuberculomas solitary or multiple in number, location of tubercles either above tentorium or below it and brain edema etc. ${ }^{7,8}$ That cases in which CT scan is not conclusive, MRI brain is done more superior to CT scan showing fine details and findings in brain. Normal examination of CSF shows glucose less than $60 \mathrm{mg} / \mathrm{dl}$ and protein content more than $45 \mathrm{mg} / \mathrm{dl}$. CSF examination takes much time and in it may be negative in more than $50 \%$ cases so it is not much sensitive for TBM. MRI is investigation of choice showing calcifications, inflammation of meningis, tuberculomas and basal meningitis.

\section{Patients and Methods}

This is a cross sectional study done in a teaching hospital Nishter Hospital located in Multan, a ciy of Pakistan. This study was completed in seven months duration. All patients presented in emergency department or outpatient door of study institution with signs and symptoms of meningitis were evaluated and out of them patients with tuberculous meningitis were selected for study. These cases were belonging to both male and female populations and having different age groups. Proper history was taken, thorough physical examination was done, CT scan was done in all cases and where CT scan was not conclusive, MRI was done. Lumber Puncture was done and $5 \mathrm{ml} \mathrm{CSF} \mathrm{taken} \mathrm{from} \mathrm{all} \mathrm{cases} \mathrm{and} \mathrm{sent} \mathrm{for}$ examination to the hospital laboratory. All necessary investigations were done such as CBC with ESR, RFTs, LFTs. A performa was designed containing relevant questions such as age, presenting complaints, durations of disease, family history of tuberculosis or in the patient himself and any associated disease etc. Those cases having any other chronic disease with TBM were not included in the study. Data collected was analyzed using statistical software and Microsoft office version 2017. Results were calculated as frequencies and percentages. Tables and graphs were used to express the results. An inclusion and exclusion criteria was formed according to which patients having meningitis due to infection with mycobacterium tuberculosis either isolated on CSF examination or findings confirmed on CT scan and MRI. Patients with chronic diseases like CLD, IHD, or other pathologies of brain tumors, hydrocephalus due to other diseases or brain abscess were not included in this study. Proper written consent was taken from all the patients in study group and privacy of patients was maintained. Consent was also taken from the ethical committee of the hospital for conducting study.

\section{Results}

All patients presented in emergency department or outpatient door of study institution with signs and symptoms of meningitis were evaluated and out of them patients with tuberculous meningitis were selected for study. These cases were belonging to both male and female populations and having different age groups. Proper history was taken, thorough physical examination was done, CT scan was done in all cases and where CT scan was not conclusive, MRI was done. There were total 116 cases diagnosed with tuberculous meningitis presenting during study duration. 64(55.2\%) were female and 52(44.8\%) were male patients. Range of their ages was $15-73$ years with mean age of $45 \pm 17.8$ years. There were $11(17.2 \%)$ female and $14(26.9 \%)$ male cases between $15-25$ years, $13(20.3 \%)$ female and $16(30.8 \%)$ male cases between 26-35 years, $15(23.4 \%)$ female and 9(17.3\%) male between 36-45 years, $10(15.6 \%)$ female and $6(11.5 \%)$ male between 46-55 years and $7(10.9 \%)$ female and $3(5.8 \%)$ male cases were above 65 years. Presenting complaints were fever in 59(92.2\%) females and 46(88.5\%) male cases, headache was present in $62(96.8 \%)$ female and 48(92.3\%) male cases, signs of meningism were present in $51(79.7 \%)$ female and $3.7(71.2 \%)$ male cases and $12(18.7 \%)$ female and $5(9.6 \%)$ male cases presented in coma. Findings on CT scan were hydrocephalus in $78(67.2 \%)$ cases, edema in $42(36.2 \%)$ and infarction in $13(11.2 \%)$ cases. On MRI brain hydrocephalus was seen in $81(69.8 \%)$ cases, tuberculomas in $86(74 \%)$ and infarcts in $14(12.1 \%)$ were seen. Solitary tuberculomas were present in $22 \%$ cases and multiple in $64 \%$ cases. 


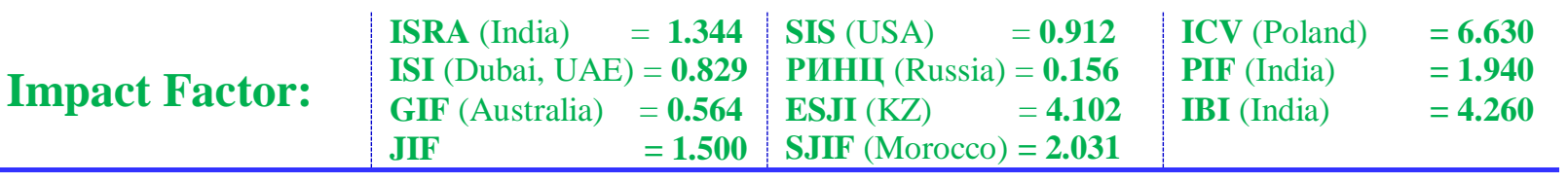

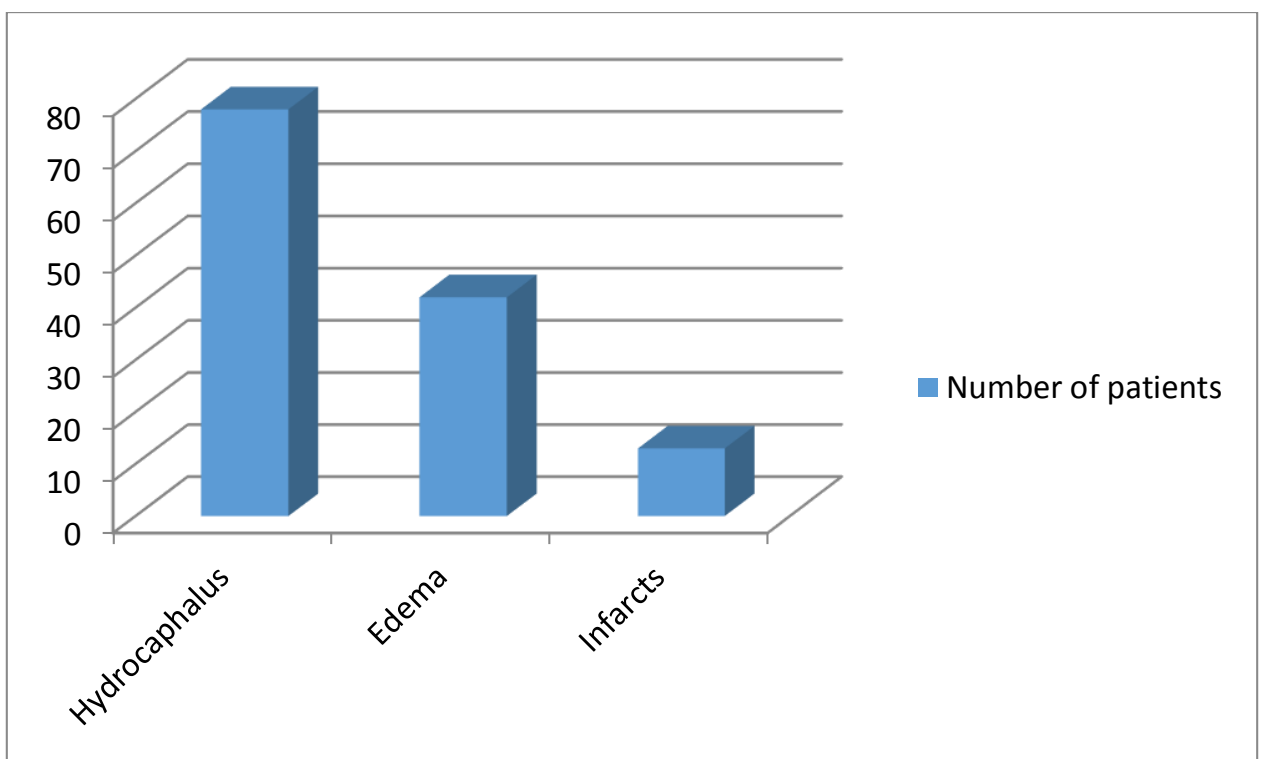

Figure-1 CT scan brain findings in TBM patients $(n=116)$

\section{Gender distribution of cases}

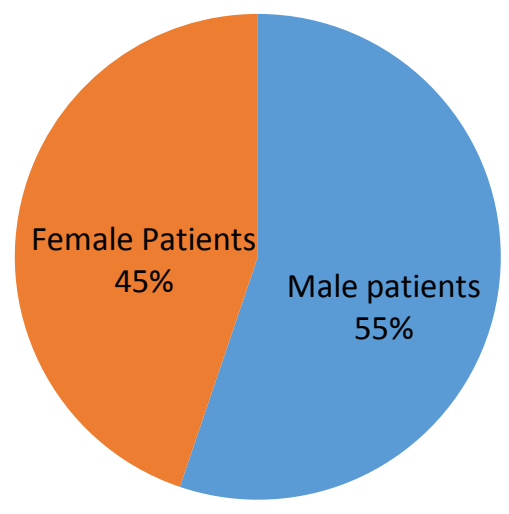

Age distribution of cases among male and female patients

Table-1

\begin{tabular}{|c|c|c|c|c|}
\hline Age groups (years) & \multicolumn{2}{|c|}{ Female patients } & \multicolumn{2}{c|}{ Male Patients } \\
\hline & $\mathbf{N}$ & $\mathbf{\%}$ & $\mathbf{N}$ & \multicolumn{2}{c|}{} \\
\hline $15-25$ & 11 & 17.2 & 14 & 26.9 \\
\hline $26-35$ & 13 & 20.3 & 16 & 30.8 \\
\hline $36-45$ & 15 & 23.4 & 9 & 17.3 \\
\hline $46-55$ & 10 & 15.6 & 6 & 11.5 \\
\hline $56-65$ & 8 & 12.5 & 4 & 7.7 \\
\hline Above 65 & 7 & 10.9 & 3 & 5.8 \\
\hline Total & $\mathbf{6 4}$ & & $\mathbf{5 2}$ & \\
\hline
\end{tabular}




\begin{tabular}{l|lr|ll|ll} 
& ISRA (India) & $=\mathbf{1 . 3 4 4}$ & SIS (USA) & $=\mathbf{0 . 9 1 2}$ & ICV (Poland) & $=\mathbf{6 . 6 3 0}$ \\
Impact Factor: & ISI (Dubai, UAE) $=\mathbf{0 . 8 2 9}$ & PUH (Russia) $=\mathbf{0 . 1 5 6}$ & PIF (India) & $=\mathbf{1 . 9 4 0}$ \\
& GIF (Australia) & $=\mathbf{0 . 5 6 4}$ & ESJI (KZ) & $=4.102$ & IBI (India) & $=\mathbf{4 . 2 6 0}$ \\
& JIF & $=\mathbf{1 . 5 0 0}$ & SJIF (Morocco) & $=2.031$ & & \\
\hline
\end{tabular}

Frequency of presenting complaints in male and female cases with TBM

Table-2

\begin{tabular}{|l|c|c|c|c|}
\hline \multicolumn{1}{|c|}{$\begin{array}{c}\text { Presenting } \\
\text { complaints }\end{array}$} & \multicolumn{2}{c|}{ Female Patients } & \multicolumn{2}{c|}{ Male Patients } \\
\hline & $\mathrm{N}$ & $\%$ & $\mathrm{~N}$ & $\%$ \\
\hline Fever & 59 & 92.2 & 46 & 88.5 \\
\hline Headache & 62 & 96.8 & 48 & 92.3 \\
\hline Meningism & 51 & 79.7 & 37 & 71.2 \\
\hline Coma & 12 & 18.7 & 5 & 9.6 \\
\hline
\end{tabular}

\section{DISCUSSION}

Meningitis is inflammation of meningism mostly due to infection by virus or bacteria but may also be caused by trauma. ${ }^{9,10}$ In bacterial causes mycobacterium tuberculosis is very common causing tuberulous meningitis. In this disease cranial nerve palsy occurs frequently and involving facial nerve and occulomotor nerve commonly. ${ }^{11}$ These cases present with signs and symptoms related to CNS. Meningitis is a very common neurological disease in which inflammation of leptpmeningis occur. This leads to hydrocephalus of non obstructing type. Intracranial pressure is raised causing headache and cranial nerves palsy, decreased in vision etc. ${ }^{12}$ Meningitis may be due to viral or bacterial infection and trauma. Mycobacterium tuberculosis is a common cause of meningitis. It is common in people having previously tuberculous infection or positive family history of pulmonary tuberculosis. ${ }^{13}$ In our study findings on CT scan were hydrocephalus in $78(67.2 \%)$ cases, edema in $42(36.2 \%)$ and infarction in $13(11.2 \%)$ cases. On MRI brain hydrocephalus was seen in $81(69.8 \%)$ cases, tuberculomas in $86(74 \%)$ and infarcts in $14(12.1 \%)$ were seen. Solitary tuberculomas were present in $22 \%$ cases and multiple in $64 \%$ cases. There are various investigations for diagnosing TBM such as CT scan brain, MRI brain and CSF culture and examination. ${ }^{14}$ In most of the cases mycobacterium is isolated on CSF culture. Suitable antibiotic treatment is very effective against it. Initial management includes airway management, maintaining circulation assessing GCS and management of fever and broad spectrum antibiotic therapy until unless culture sensitivity is obtained. According to different studies frequency of hydrocephalus was $11-75 \%$ in patients with tuberculous meningitis. ${ }^{15}$ This is a cross sectional study done in a teaching hospital Nishter Hospital located in Multan, a ciy of Pakistan. This study was completed in seven months duration. All patients presented in emergency department or outpatient door of study institution with signs and symptoms of meningitis were evaluated and out of them patients with tuberculous meningitis were selected for study. ${ }^{16}$ These cases were belonging to both male and female populations and having different age groups. Proper history was taken, thorough physical examination was done, CT scan was done in all cases and where CT scan was not conclusive, MRI was done. Lumber Puncture was done and $5 \mathrm{ml}$ CSF taken from all cases and sent for examination to the hospital laboratory. There were total 116 cases diagnosed with tuberculous meningitis presenting during study duration. $64(55.2 \%)$ were female and 52(44.8\%) were male patients. Range of their ages was $15-73$ years with mean age of $45 \pm 17.8$ years. . In CT scan features of TBM reveal clearly such as hydrocephalus, presence of tuberculomas solitary or multiple in number, location of tubercles either above tentorium or below it and brain edema etc. That cases in which CT scan is not conclusive, MRI brain is done more superior to CT scan showing fine details and findings in brain. Early diagnosis of patients and prompt treatment can reduce morbidity and mortality associated with this disease.${ }^{17}$ Definite treatment is to reduce intracranial pressure and complete course of ATT drugs.

\section{Conclusion}

Among various causes of meningitis bacterial cause was found common in this study. Tuberculous meningitis is a common form of meningitis occurring in both genders but frequently occurs in females. CT scan and MRI are very helpful in diagnosing TBM. Lumber puncture is not much sensitive for this disease as it is negative in most of cases having disease. Most common presenting symptoms were fever, headache and meningism while coma may be present in few cases. Main line of treatment is to manage vitals and to decrease intracranial pressure. 


\begin{tabular}{l|lr|ll|ll} 
& ISRA (India) & $=\mathbf{1 . 3 4 4}$ & SIS (USA) & $=\mathbf{0 . 9 1 2}$ & ICV (Poland) & $=\mathbf{6 . 6 3 0}$ \\
Impact Factor: & ISI (Dubai, UAE) $=\mathbf{0 . 8 2 9}$ & PUHL (Russia) $=\mathbf{0 . 1 5 6}$ & PIF (India) & $=\mathbf{1 . 9 4 0}$ \\
& GIF (Australia) & $=\mathbf{0 . 5 6 4}$ & ESJI (KZ) & $=\mathbf{4 . 1 0 2}$ & IBI (India) & $=\mathbf{4 . 2 6 0}$ \\
& JIF & $=\mathbf{1 . 5 0 0}$ & SJIF (Morocco) & $=\mathbf{2 . 0 3 1}$ & & \\
\hline
\end{tabular}

\section{References:}

1. Leonard JM, Des Prez RM. (1990) Tuberculous meningitis. Infect Dis Clin North Am 1990; 4: 769-87.

2. Andronikou S, Wieselthaler N, Smith B, Douis H, Fieggen AG, van Toorn R, et al. (2005) Value of early follow-up CT in paediatrictuberculous meningitis. PediatrRadiol 2005; 35: 1092-9.

3. Sobri M, Merican JS, Nordiyana M, Valarmathi S, Al-Edrus SA. (2006) Neuroimaging features of tuberculous meningitis. Med J Malaysia 2006; 61: 36-40.

4. Sirajus S, Khalid M, Naqvi IH, Akhter ST, Abbasi A. (2013) Clinical course, complications and predictors of mortality in patients with tuberculous meningitis an experience of fifty two cases at Civil Hospital Karachi, Pakistan J Pak Med Assocvol 63, may 2013.

5. Etlik Ö, Evirgen Ö, Bay A, Yilmaz N, Temizöz O, Irmak H, et al. (2004) Radiologic and clinical findings in tuberculous meningitis. Eur J Gen Med 2004.

6. Cherian A, Thomas SV. (2011) Central nervous system tuberculosis. Afr Health Sci 2011;11:116-27.

7. George EL, Iype T, Cherian A, Chandy S, Kumar A, Balakrishnan A, Vijayakumar K. (2012) Predictors of mortal ity in patients with meningeal tuberculosis. Neurol India 2012;60:18-22.

8. Bernaerts A, Vanhoenacker FM, Parizel PM, et al. (2003) Tuberculosis of the central nervous system: overview of neuroradiological findings. Eur. Radiol. 13(8),1876-1890 (2003).

9. Wasay M, Kheleani BA, Moolani MK, Zaheer J, Pui M, Hasan S, et al. (2003) Brain CT and
MRI findings in 100 consecutive patients with intracranial tuberculoma. J Neuroimaging 2003; 13: 240-7.

10. Sonmez G, Ozturk E, Sildiroglu HO, Mutlu H,Cuce F, Senol MG, et al. (2008) MRI findings of intracranial tuber culomas. Clin Imaging 2008; 32: 88-92.

11. Off enbacher H, Fazekas F, Schmidt R, Kleinert R, Payer P, Kleinert G, et al. (1991) MRI in tuberculousmenin goencephalitis: report of four cases and review of the neuroimaging literature. J Neurol 1991; 238: 340-4.

12. Tarakad S Ramachandran, Frederick M Vincent $\mathrm{Sr}$, Tuberculousmeningitis [online] (2011) [cited 10th April 2014]. Available from(http://emedicine.med scape.com/article/1166190-overview).

13. Kent SJ, Crowe SM, Yung A, Lucas CR, Mijch AM. (1993) Tuberculous meningitis: a 30-year review. Clin Infect Dis 1993; 17: 987-94.

14. Qureshi HU, Merwat SN, Nawaz SA, Rana AA, Malik A,Mahmud MK, et al. (2002) Predictors of inpatient mortality in 190adult patients with tuberculous meningitis. J Pak Med Assoc 2002; 52: $159-63$

15. Thwaites GE, Tran TH. (2005) Tuberculous meningitis: many questions, too few answers. Lancet Neurol. 4(3),160-170 (2005).

16. Rich AR, McCordock HA. (1933) The pathogenesis of tuberculous meningitis. Bull. John Hopkins Hosp. 52,2-37 (1933).

17. Fazel P A, Makki KU, Haroon H, Soomro I B, Afzal U. (2006) Clinical spectrum and outcome of patients with tuberculous meningitis. Med Channel 2006; 12: 21-3. 